\title{
Information Support of Pedagogical Process for the Children Experiencing Difficulties with Acquisition of Preschool Educational Programs
}

\author{
Likhachyova Ye.N \\ Bobrova V \\ Ogoltsova Ye.G
}

Doi:10.5901/mjss.2016.v7n2p306

\begin{abstract}
Searching for new forms and methods of education of children experiencing difficulties in assimilation of the preschool educational program caused an attempt of theoretical, experimental justification of the development of computer technologies, as well as their effective use in educational and training process of preschool organizations. Based on the development and deployment in the educational process of programs for computer support of education of the children experiencing difficulties in assimilation of the preschool educational program. For the first time there is developed and introduces in the educational process the electronic educational and methodological support of the training process for children experiencing difficulties in assimilation of the preschool educational program. As a result of the obtained data when introducing in the educational process the electronic educational and methodological support of the process of training children experiencing difficulties in assimilation of the preschool educational program there is observed positive dynamics in assimilation of the program material.
\end{abstract}

Keywords: Information support, principles of creation of computer programs, preschool age, learning difficulties

\section{Introduction: Problem of High-quality Training and Education of Children of Preschool Age at the Present Stage}

The base of all educational process is preschool education. Now one of the main problems of the first step of all education system is the problem of improvement of quality of education. The analysis of psychology and pedagogical literature concerning high-quality education of children of preschool age testifies that the assessment of quality of educational process should not be limited to fixing on existence in groups of preschool institutions of well-trained, capable children, but has to estimate pedagogical process from the point of view of its contribution to development of the personality of each child. Relevance of this situation can be attributed to heterogeneity of indicators, under the influence of which the child's development takes place (congenital organism properties, environment of child'sdevelopment, education conditions). Level variability of factors of child's development causes individual distinctions of children which, first of all, are shown at the rate of their mental development. Besides standard level of mental development, in some children its advancing or delay can be observed. So, the children having identical calendar age can be at different stages of development, that is can have variable indicators: biological age, degree of formation of mental processes and opportunity for acquisition of educational preschool programs.

Now some certain part of children with the detained level of mental development on a number of the objective reasons are pupils of not specialized, but mass preschool educational institutions. This category of children experiences systematic difficulties in traditional conditions of training and education in acquisition of program material.

\section{Role of Informatization of Education in the Course of High-quality Training and Education of the Children Experiencing Difficulties in Acquisition of Program Material of Preschool Educational Institution}

The current state of society is characterized by intensive penetration of information technologies into all spheres of human activity. Now, in the sphere of use of computer technologies in education, including preschool, it is possible to allocate two main directions (Kisselev, 1997).

The first of them - theoretical - means use of computers for studying of theoretical fundamentals of computer science, as the science about information processes. Its main objective is development of information culture of future inhabitants of the new information society, consisting of formation of scientific outlook, operational style of thinking, 
abilities to work on the computer.

The second direction - applied - assumes use of computers as a technical tool of training on educational programs. Within this direction the computer acts not just as the information transfer accelerator in educational process, but opens essentially new opportunities in the field of education (Polat, 2000).

Use of the computer in pedagogical process allowed to reveal a number of advantages in comparison with traditional forms of education:

- information presentation on the computer screen in a game form causes interest in children and desire to keep on working;

- the computer in itself bears figurative type of information clear to preschool children who are not able to read and write yet;

- the computer gives opportunity of individualization of training, at the same time, in the course of the activity on the computer the child acquires self-confidence;

- the computer allows to model such life situations which the child cannot see in everyday life.

Thanks to above-mentioned advantages, use of the computer in the course of training and education of the children experiencing difficulties in acquisition of preschool educational program, allows to level their specific features of development and to reach the following results (Beloussova, 2013):

- children acquire concepts of form, color and size more easily;

- concepts of number and set are comprehended more deeply;

- $\quad$ ability to orient on the planes and in space, in statics and movement develops more quickly;

- attention and memory are trained;

- reading and writing skills are acquired earlier;

- lexicon develops in an active way;

- fine motor skills are developed, fine coordination of movements of eyes and hands is formed;

- sensorimotor skills are developed: time of both simple reaction and choice reaction decreases.

- determination and concentration are developed;

- imagination and creative abilities are developed;

- elements of eye-mindedness and theoretical thinking are developed, which allow children to anticipate a situation, to plan the actions and not only "to execute", but also "to create";

- skills of communicative communication by a method of mastering the ways of understanding of emotional conditions of other people are developed.

At the same time the qualitative analysis of modern computer means for children of preschool age, carried out by us, revealed that the existing automated educational and developing computer programs are intended for children with a standard level of development of mental processes and, therefore, the main objective, along with training and education, is development of mental processes of children. They are not focused on the preschool children experiencing difficulties in acquisition of program material and therefore do not pursue the correctional aims. During the work with these computer programs among the children experiencing difficulties in acquisition of preschool educational program (570 children of preschool age took part in the survey), the following features were observed: fast occurrence of exhaustion (76\%), attention concentration decreased (84\%), interest in educational process decreased (92\%), irritability and negativism appeared (54\%).

The created contradiction caused the need of definition of the principles of creation of the automated educational and developing programs for the children experiencing difficulties in acquisition of program material of preschool educational program (Leonova, 2008).

\section{Development and Implementation of the Automated Educational and Developing Computer Programs for High-quality Training and Education of the Children Experiencing Difficulties in Acquisition of Preschool Educational Programs}

The automated educational and developing programs for the children experiencing difficulties in acquisition of program material have to be developed on the basis of the following didactic principles (Leonova, 2010):

- scientific character of the maintenance of a technique of formation of cognitive, emotional processes and personality of a child as a whole;

- compliance and interrelation of substantial and procedural parts of formation of cognitive, emotional processes and personality of a child as a whole;

- development of children in the course of work with the program through an education individualization; 
- availability and feasibility in achievement of the objectives;

- rational ratio of informativity, entertaining and visual appeal;

- existence of a positive emotional mood background of the child.

On the basis of the revealed principles educational and developing computer programs for the children experiencing difficulties in acquisition of program material were developed. For example we will consider structure and contents of the developed automated training program "Ladder". The automated training program (ATP) has no age addressing and is focused on a level of development of mental processes of children. Considering mental features of ATP users, it is not overloaded with excessive sound and visual effects.

ATP consists of three consecutive levels with increasing degree of complexity. In turn, each level contains a series of tasks for development of the following mental processes: perception, attention, thinking, memory, emotional sphere. Tasks of each level are approached to age steps of development of mental processes of children of preschool age.

Transition from one task to another is possible only after successful completion of the previous task. If there is a mistake in performance of any task at any level there is a return to the beginning of this task. The algorithm of ATP is presented in figure 1.

After opening the main page of the automated training program we see the start-up screen (figure 2) and the link "Left-click in any place".

Figure 2 - Main screen

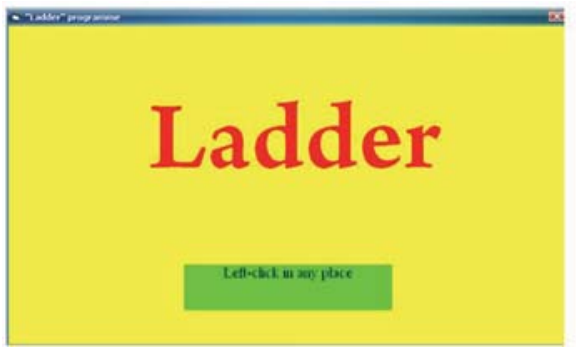

After moving to the following page there is a short instruction on application and settings of the program: difficulty levels, pictures delay time (figure 3 ).

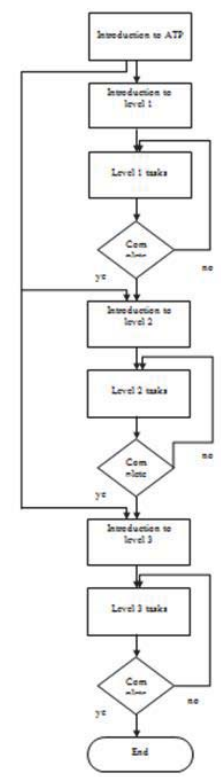

Figure 1 - "Ladder" ATP algorithm 


\section{Figure 3 - Settings screen}

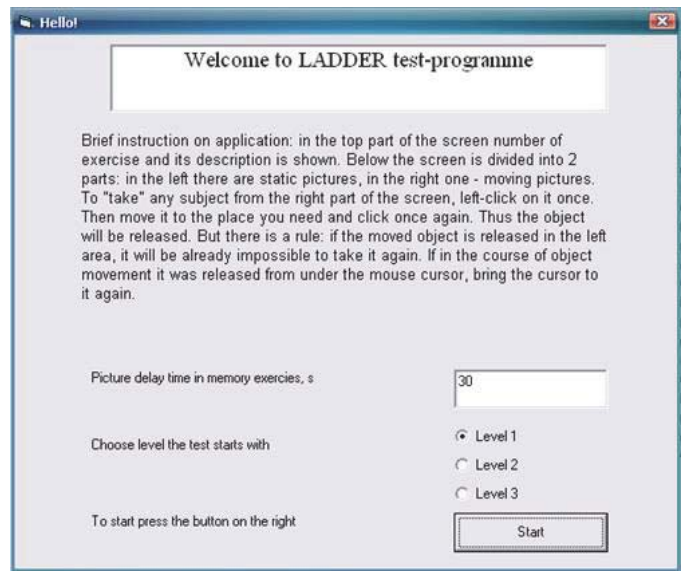

After selection of parameters and pressing of the Begin button the program starts. On the page the chosen level is shown, and there is an opportunity to start work with any group of tasks you like - perception, memory, thinking or the emotional sphere (figure 4).

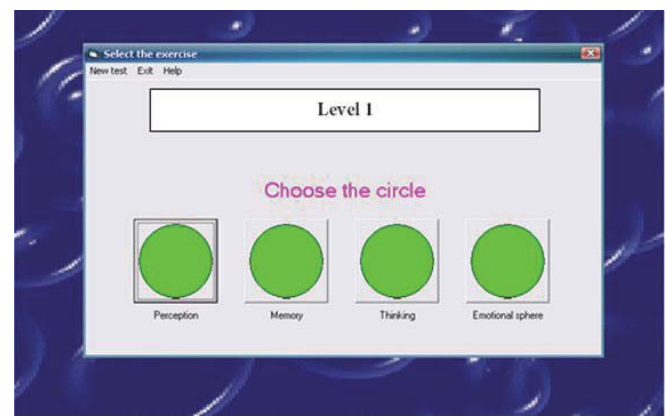

Figure 4 - Group of tasks selection page

Each group of tasks of the automated training program "Ladder" has three difficulty levels.

In the main menu of the window you can quit or choose another test.

After selection of the link "Perception" you are transferred to the pages containing exercises on development of perception (figure 5).

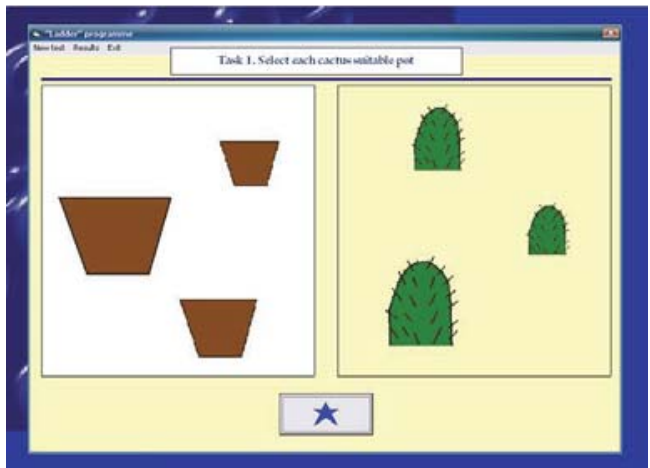

Figure 5 - Example of task in "Perception" section. 
All exercises besides the visual instruction on performance of exercise have synchronous sound accompaniment.

If you fail to do the exercise correctly, there is a graphic image appearing on the screen - "sad face" (figure 6) and there is a transition to the beginning of this exercise. In case of correct performance there is a graphic image - "smiling face" (figure 7) and transition to the following task.

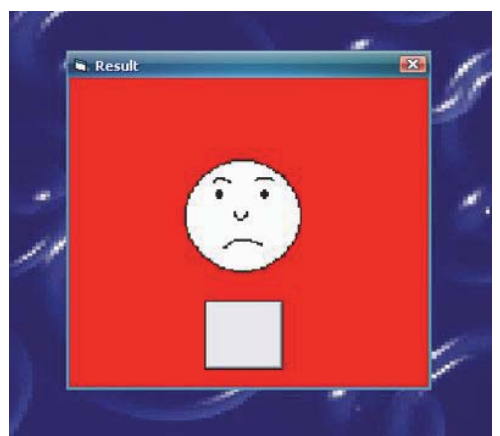

Figure 6 - Failure

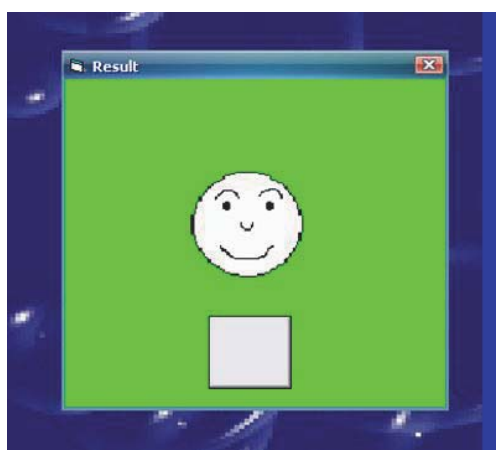

Figure 7 - Successful completion

During the further work with the program after selection of the sections "Memory", "Thinking", "Emotional Sphere" there is transition to the relevant groups of tasks.

After doing the exercises you can choose the link "Results" to see the results of the passed tests in a table form with interpretation of correctness of performance of all exercises by levels and sections (figure 8).

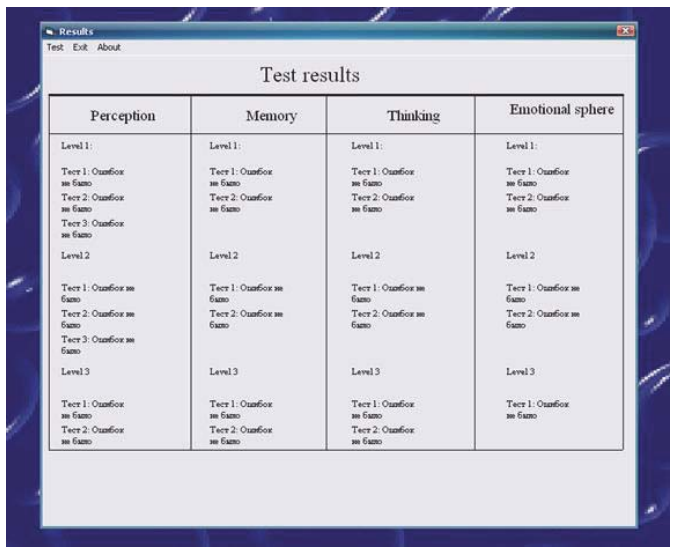

Figure 8 - Test results 
The automated training program provides a practical training on development of all mental processes: perception, memory, thinking, emotional sphere and information on developers.

As the development environment of training system Dreamweaver was chosen - it is a very convenient editor for creation of documents in HTML format. The program has an arsenal of means of visual design, sufficient to create a hypertext page of average complexity, without manual coding and work with the Code Inspector. Many operations of editing and fine tuning of hypertext documents can be executed only by means of direct work with HTML descriptors (Warschauer, 2006).

The automated training program "Ladder" allows to carry out correction of mental processes in children, at the same time individualizing their training and education.

For determination of efficiency of the developed computer programs (on the basis of certain didactic principles) we carried out psychology and pedagogical experiment.

The analysis of results of experimental work showed that application of the computer technologies developed taking into account the didactic principles of training and education of children of the studied category has a number of advantages: computer literacy allows to increase the scope of knowledge, activates accuracy and specificity of thought, develops attention, memory, precision, creativity. At the same time, application of computer technologies allows to improve the following processes.

1. Activate the cognitive and emotional-volitional sphere of the child. Thus, emergence in world practice of more and more perfect software, its adaptation to the abilities of preschool children allows not only to enrich their knowledge, but also to use the computer for better familiarization with subjects and the phenomena which are out of the child's own experience, as well as raise creativity of the child, ability to operate with symbols on the monitor screen that promotes transition optimization from eye-mindedness to abstract thinking. Use of creative and acting games creates additional motivation when forming educational activity. Individual work with the computer increases number of situations, which the child can solve on his own, and that considerably develops his emotional-volitional sphere and the personality as a whole.

2. Provide smooth transition to educational activity. Elementary school demands from children to replace the leading activity from game for education, which, as we know, is considerably complicated in the studied group of children. This transition often happens to be very painful and is accompanied by psychological problems, addition of secondary disorders, which can be avoided with the help of game opportunities of the computer in combination with the didactic ones: visual presentation of information, providing feedback between the training program and the child, great opportunities of encouragement of the correct actions, individual work style etc.

3. Refresh the previously acquired knowledge. The most part of the knowledge gained by such children in traditional classes is not used by the latter in class-free time, and its practical value is lost, and profoundness significantly decreases. The game computer environment permits to refresh them, and the desire to play leads to motivation of its acquisition.

4. Partially discharge high emotional tension and create more favorable climate in other lessons. This results from the fact that high degree of emotionality belongs to psychological features of these children, which considerably restrains rather strict framework of educational process in traditional lessons.

5. Develop fine motor skills, create motor coordination and coordination of joint activity of visual and motor analyzers, disturbance of which is frequently observed in these children. This defect can interfere with their further development, become an obstacle not only in acquisition of an educational program, but also in communication with peers. Application of computer technologies can quite naturally, without additional special classes, develop necessary visual and motor coordination.

6. Develop mental processes (memory, thinking, attention). Computer technologies permit to increase the volume of single-step memorization, develop both visual and aural memory. They promote improvement of attention concentration, as well as improve functions of switching and distribution of active attention. They broaden horizons of the child, raise the comprehension level. They teach to apply available experience to a modified situation.

The carried out work on development and check of efficiency of use of computer programs for training and education of children of preschool age experiencing difficulties in training and education, on the basis of the revealed didactic principles does not claim to be finished scientific applied research and testifies to the need of further development of this direction. Development of subject computer training and developing programs for effective training and education of the children experiencing difficulties in acquisition of preschool educational program have to become further stages of work. 


\section{References}

Kisselev B.G.Home computer in education system // Educational computer software. 2007. № 1 (10). Pp.50-55.

New pedagogical and information technologies in educational system/Under the editorship of E.S. Polat. M.: Publishing center «Academy», 2000. 210p.

Beloussova L.I., Olefirenko N.V. Didactic potential of digital educational resources for school children // Educational Technology \& Society. 2013. V. 16. N 1. Pp. 584-599.

Leonova L.A. Some results and prospects of the research problem "Computer and health of the child"// New research. 2008. Pp.53-68.

Preschool and computer: medical and hygiene recommendations / ed. Leonova L.A. Moscow: Publisher Moscow psycho-social institution; Voronezh: MODEK, 2010. 62 p.

Warschauer M. Laptops and Literacy: Learning in the Wireless Classroom. New York: Teachers College Press, 2006. 192 p. 